\title{
A ação do Pibid no ambiente escolar: a utilização do jogo balanceamento químico e a confecção de um videoclipe no processo de ensino e aprendizagem de química
}

The action of Pibid in the school environment: the use of chemical balancing and the making of a video clip in the process of teaching and learning chemistry Ana Nery Furlan Mendes Carlos Duarte Silva Luciara Costa de Souza Tamires Cesquine Alves

Resumo: O ensino de química requer que metodologias alternativas sejam propostas para torná-lo mais atrativo e contextualizado para os alunos. Este estudo possibilitou uma reflexão sobre diferentes recursos didáticos e avaliou como esses recursos são recebidos e utilizados pelos alunos na aprendizagem de alguns conteúdos de química. A pesquisa foi realizada em 8 turmas do ensino médio de uma escola pública do município de São Mateus/ES, sendo 6 de primeira série e 2 de segunda série. Para as turmas da primeira série foi proposto que os alunos criassem uma paródia e construíssem um videoclipe sobre os conteúdos da Tabela Periódica. Para as turmas da segunda série um jogo sobre o Balanceamento de Reações Químicas foi desenvolvido pelos pibidianos e aplicado aos alunos, como forma de complementar 0 conteúdo explanado pela professora regente em sala de aula. O critério adotado para a seleção dos conteúdos foi a dificuldade que os alunos apresentam na compreensão desses assuntos. Para avaliar a prática metodológica, nas primeiras séries, um questionário foi aplicado aos alunos ao final da proposta, e nas segundas séries utilizou-se a observação e o registro das impressões dos alunos. A professora e os bolsistas do PIBID mediaram o processo de ensino e aprendizagem, motivando os alunos a participarem das atividades. As metodologias tiveram uma ótima aceitação por parte dos alunos, que afirmaram ter aprendido mais sobre o conteúdo em estudo. Para os bolsistas do PIBID, a realização dessas aulas foi uma forma de vivenciar a realidade da sala de aula e construir sua identidade como docente.

Palavras-chave: Ensino de química, metodologia alternativa, tabela periódica, reações químicas.

Abstract: The teaching of chemistry requires that alternative methodologies be proposed to make it more attractive and contextualized for students. This study allowed a reflection on different teaching resources and evaluated how these resources are received and used by students in the learning of some chemistry contents. The research was carried out in 8 high school classes of a public school in the city of São Mateus/ES, being 6 of first grade and 2 of second grade. For the first grade classes it was proposed that the students create a parody and build a video clip about the contents of the Periodic Table. For the second grade classes a game about the Balance of Chemical Reactions was developed by the Pibidians and applied to the students, as a way to complement the content explained by the teacher in class. The criterion adopted for the selection of the contents was the difficulty that the students present in understanding these subjects. To assess methodological practice, in the first grades, a questionnaire was applied to students at the end of the proposal, and in the second grades, observation and recording of students' impressions was used. The teacher and the PIBID scholarship holders mediated the teaching and learning 
process, motivating the students to participate in the activities. The methodologies were very well accepted by the students, who claimed to have learned more about the content under study. For PIBID scholarship holders, the realization of these classes was a way to experience the reality of the classroom and build their identity as teachers.

Keywords: Teaching chemistry, alternative methodology, periodic table, chemical reactions.

\section{Introdução}

A Química é uma disciplina que faz parte do programa curricular do ensino fundamental e médio. Possibilita aos alunos a compreensão das diversas transformações químicas que ocorrem no mundo, de forma ampla e integrada, para que estes possam entender que ela está ao nosso redor e, ao mesmo tempo, faz parte de nós mesmos (PCNEM, 1999).

Entretanto, ainda se verifica a presença de aulas desconectadas da realidade do aluno. O mesmo não entende o porquê do estudo de determinados conteúdos, e surge a temida pergunta: Onde eu vou usar isso na minha vida? Segundo Silva e colaboradores (2012, p. 189), "o ensino de química tem passado por momentos de intensa reflexão, devido aos elevados índices de reprovação e evasão, pois as aulas de química são vistas pelos alunos como algo maçante, com memorização de conceitos e fórmulas apresentados nos livros didáticos".

É notório que os alunos apresentam uma certa dificuldade em compreender alguns conceitos químicos, pois a Química é uma ciência abstrata. Conteúdos importantes como Tabela Periódica, lecionado na $1^{\text {a }}$ série do Ensino Médio, e Balanceamento de Reações Química, ministrado na $2^{a}$ série do Ensino Médio, são exemplos de assuntos que os alunos apresentam certa dificuldade. Segundo Soares (2019, p. 8),

A Tabela Periódica é uma ferramenta fundamental no ensino de Química e seu entendimento é substancial para o aproveitamento em diversos outros conteúdos dessa ciência. Contudo, o ensino que é oferecido aos alunos, na maioria das vezes, não relaciona a evolução histórica dos elementos com a sua organização e classificação. Dessa forma, o aluno observa a Tabela Periódica como um quadro de elementos que necessita decorar, sem significação. 
Sobre o balanceamento de reações químicas, Piedade e colaboradores (2016) afirmam que a habilidade em balancear equações químicas é uma regra crucial para o entendimento de reações químicas, assunto este importante para a compreensão de fenômenos no nosso cotidiano.

Para que o ensino de Química seja atrativo e favoreça a aprendizagem, o mesmo deve ser voltado para o cotidiano do aluno, pois a Química é uma ciência presente em diversos fenômenos que acontecem no nosso dia a dia. Não faz sentido estuda-la de forma desconectada. O PIBID (Programa Institucional de Bolsa e Iniciação à Docência) tem o papel de auxiliar o professor em formação, através do desenvolvimento de metodologias alternativas de ensino, de forma a tornar a aula de Química mais dinâmica e voltada à realidade do aluno. Um dos objetivos do Programa é,

Inserir os licenciandos no cotidiano de escolas da rede pública de educação, proporcionando-lhes oportunidades de criação e participação em experiências metodológicas, tecnológicas e práticas docentes de caráter inovador e interdisciplinar que busquem a superação de problemas identificados no processo de ensino-aprendizagem (CAPES, 2008).

O uso de metodologias alternativas de ensino, como jogos, Histórias em Quadrinhos e recursos audiovisuais, podem ser utilizados para tornar o ensino de Química mais atrativo, favorecendo, assim, a aprendizagem do aluno. Neste trabalho, utilizou-se a música e o jogo didático como instrumentos facilitadores da aprendizagem. De acordo com Moreira, Santos e Coelho (2014, p. 42),

A música ensina o indivíduo a ouvir e a escutar de maneira ativa e refletida [...] facilita a concentração e o desenvolvimento do raciocínio, sendo também um agente cultural que contribui efetivamente na construção da identidade do cidadão. Pode até mesmo transformar conceitos espontâneos em conceitos científicos.

Sobre a utilização de jogos no ensino, Vygostsky (2007) afirma que,

Os jogos estimulam a curiosidade, a iniciativa $e$ a autoconfiança; aprimoram o desenvolvimento de habilidade linguística, mentais e de concentração; e exercitam interações sociais e trabalho em equipe. Com eles, os estudantes podem ir além da aprendizagem convencional, centrado na teoria, interagindo com $\mathrm{o}$ contexto trabalhado. Assim, seus 
pensamentos serão muito mais organizados, fundamentados e amplos aumentando a curiosidade e vontade de aprender.

Este trabalho tem o intuito de apresentar a importância dos recursos didáticos como instrumentos motivadores de socialização e interação e a participação dos bolsistas do PIBID no processo de desenvolvimento destas metodologias diferenciadas de ensino e aprendizagem.

\title{
Desenvolvimento do trabalho
}

Buscando-se alcançar o objetivo estabelecido para este trabalho, utilizamos uma abordagem de investigação de natureza qualitativa. Segundo Gil (2006, p. 21-22),

\begin{abstract}
A pesquisa qualitativa responde a questões muito particulares. Ela se preocupa, nas ciências sociais, com um nível de realidade que não pode ser quantificado. Ou seja, ela trabalha com o universo de significados, motivos, aspirações, crenças, valores e atitudes, o que corresponde a um espaço mais profundo das relações, dos processos e dos fenômenos que não podem ser reduzidos à operacionalização de variáveis.
\end{abstract}

Considerando seu delineamento, a presente pesquisa também se caracteriza como exploratória, pois objetiva "aumentar o conhecimento sobre determinado tema ou assunto, possibilitando a construção de hipóteses ou tornar a situação em questão mais explícita" (MALHEIROS, 2011, p. 32).

As metodologias alternativas foram desenvolvidas e aplicadas em turmas do ensino médio de uma escola pública do município de São Mateus/ES e tiveram como objetivo facilitar a aprendizagem dos conteúdos de Tabela Periódica e Balanceamento de Reações Químicas, pois observou-se a dificuldade de compreensão dos alunos durante as aulas teóricas.

\section{A CONSTRUÇÃO DE UM VIDEOCLIPE SOBRE TABELA PERIÓDICA}

A metodologia foi aplicada em seis turmas da $1^{\text {a }}$ série do Ensino Médio, do turno matutino, e teve o objetivo de facilitar a aprendizagem do conteúdo de Tabela Periódica de uma maneira diferenciada e divertida.

Os alunos foram incentivados através da música e da tecnologia atual, a construir um videoclipe sobre a Tabela Periódica. A professora supervisora e 
os pibidianos auxiliaram os alunos na elaboração do trabalho. Durante a construção da paródia, quando eles apresentavam alguma dúvida sobre o conteúdo, a professora e os pibidianos ajudavam a solucionar. Na construção do videoclipe, os grupos tiveram suporte para a gravação e formatação do vídeo.

A proposta foi desenvolvida em 5 etapas. A $1^{\text {a }}$ etapa consistiu na elaboração da paródia sobre a Tabela Periódica, no qual os alunos foram instruídos a pesquisar sobre o assunto, para que a paródia fosse elaborada com informações corretas. A $2^{a}$ etapa foi a criação do videoclipe musical. Nesta etapa, os alunos deveriam usar toda a sua criatividade para "contar uma história" a partir da paródia construída. A $3^{a}$ etapa foi a apresentação do videoclipe, que teve o objetivo de apresentar para a turma o trabalho realizado por cada grupo. A $4^{a}$ etapa consistiu na avaliação do trabalho, que foi realizado pela professora supervisora em parceria com os pibidianos, utilizando-se de critérios pré-selecionados. A $5^{\mathrm{a}}$ e última etapa foi a aplicação do questionário avaliativo, que teve o objetivo de verificar a opinião dos alunos sobre a metodologia proposta.

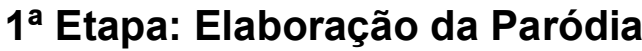

O assunto Tabela Periódica foi escolhido pela professora regente e pelos pibidianos, pois os alunos apresentam dificuldade em sua interpretação. A paródia deveria conter os seguintes itens:

1) Histórico da Tabela Periódica;

2) Como a Tabela Periódica foi organizada;

3) O que os períodos indicam sobre a estrutura dos átomos;

4) O que as famílias indicam sobre a estrutura dos átomos.

Os alunos foram divididos em grupos de até 5 componentes. Como já existem algumas paródias sobre o conteúdo de Tabela Periódica disponível na internet, foi avisado aos alunos que não seria permitido no trabalho plágio de paródias já existentes. Os alunos deveriam fazer pesquisas em livros, revistas e internet para auxiliar na construção das paródias. 
Os grupos escolheram qual seria o estilo de música utilizado para a construção da paródia.

\section{$2^{\mathrm{a}}$ Etapa: Criação do Videoclipe}

Os alunos foram informados que todos os componentes do grupo deveriam participar do videoclipe. A escolha do ambiente de filmagem deveria ser escolhida pelo grupo, ou seja, eles escolheram e determinaram o melhor lugar para filmar. Muitos grupos escolheram a própria escola como cenário, e a diretora disponibilizou o espaço e a câmera fotográfica profissional da escola para as filmagens. Para a edição dos vídeos, o pibidiano responsável por orientar os alunos, disponibilizou um horário, no turno vespertino, para atendimento aos grupos. Assim, os alunos puderam sanar suas dúvidas, tanto a respeito do conteúdo Tabela Periódica, como a respeito da formatação do videoclipe. É importante destacar que, no videoclipe, deveria conter a letra da paródia criada (legenda).

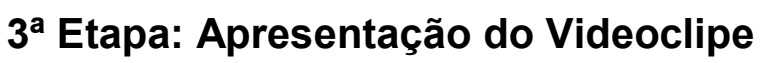

Os vídeos de uma determinada turma, foram exibidos para os alunos da respectiva sala. Usamos o projetor e a caixa de som, fornecidos pela escola, como recursos para a exibição dos vídeos. Cada grupo teve 15 minutos para a apresentação do videoclipe, sendo assim, foram necessárias 2 aulas para que todos os grupos apresentassem seu trabalho.

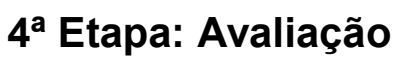

O projeto serviu como método de avaliação por parte da professora. No total, o trabalho foi avaliado em 12,0 pontos. Os critérios de avaliação, bem como as observações realizadas e a nota para cada critério estão apresentadas no Quadro 1. 
Quadro 1 - Critérios de avaliação utilizados para a avaliação do trabalho produzido pelos alunos.

\begin{tabular}{|l|l|l|}
\hline Critérios & Observações realizadas & $\begin{array}{l}\text { Nota } \\
\text { atribuída }\end{array}$ \\
\hline $\begin{array}{l}\text { Organização do } \\
\text { grupo }\end{array}$ & $\begin{array}{l}\text { O grupo entregou o trabalho na data marcada? } \\
\text { O grupo se comportou durante as apresentações? }\end{array}$ & $\begin{array}{l}2,0 \\
\text { pontos }\end{array}$ \\
\hline $\begin{array}{l}\text { Construção da da } \\
\text { paródia }\end{array}$ & $\begin{array}{l}\text { A paródia contém as informações que foram } \\
\text { solicitadas? } \\
\text { A paródia contém informações corretas sobre o } \\
\text { assunto Tabela Periódica? }\end{array}$ & $\begin{array}{l}5,0 \\
\text { pontos }\end{array}$ \\
\hline $\begin{array}{l}\text { Construção do do } \\
\text { videoclipe }\end{array}$ & $\begin{array}{l}\text { Foi contada uma história no videoclipe? } \\
\text { A produção audiovisual ficou de qualidade? } \\
\text { O grupo adicionou a letra da paródia no videoclipe? }\end{array}$ & $\begin{array}{l}5,0 \\
\text { pontos }\end{array}$ \\
\hline
\end{tabular}

Fonte: Elaborado pelo autor.

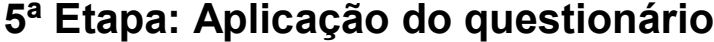

$\mathrm{Na}$ aula seguinte ao término das apresentações dos videoclipes, foi aplicado um questionário, contendo 5 (cinco) questões, visando a avaliação da metodologia proposta. Foi disponibilizado 15 minutos da aula para que os alunos respondessem o questionário. Na Figura 1 tem-se o questionário aplicado.

Figura 1 - Questionário aplicado aos alunos das primeiras séries do Ensino Médio.

\begin{tabular}{|c|}
\hline $\begin{array}{l}\text { Formulário de pesquisa metodológica } \\
\text { 1. Você gostou da metodologia que foi trabalhada? Se SIM, justifique. Se NẢO, } \\
\text { por qual motivo? }\end{array}$ \\
\hline $\begin{array}{l}\text { 2. Quais dos seguintes itens você teve dificuldade ao realizar a paródia? } \\
\begin{array}{ll}\text { ( ) Criar. } & \text { ( ) Editar o vídeo. } \\
\text { ( ) Filmar. } & \text { ( ) Elaborar a música. } \\
\text { ( ) Cantar. } & \text { ( ) Trabalhar em equipe. }\end{array}\end{array}$ \\
\hline 3. O que pode ser melhorado para essa metodologia? \\
\hline 4. Qual foi o maior incentivo para esse trabalho? \\
\hline $\begin{array}{l}\text { 5. Atribui uma nota de } 1 \text { a } 5 \text { se a construção da paródia da tabela periódica de } \\
\text { alguma forma contribuiu para o seu conhecimento. } \\
\text { ( ) Contribuiu para o meu conhecimento. } \\
\text { ( ) Incentivo por notas. } \\
\text { ( ) Se sentiu mais motivado aos estudos. }\end{array}$ \\
\hline
\end{tabular}

Fonte: Elaborado pelo autor 
JOGO "BALANCEAMENTO QUÍMICO" COMO METODOLOGIA DE ENSINO PARA APRENDIZAGEM DAS REAÇÕES QUIIMICAS

A metodologia foi aplicada para 54 alunos de 2 turmas da $2^{\text {a }}$ série do ensino médio, do turno matutino, com o objetivo de reforçar a explicação da professora, pois foi observada a dificuldade dos alunos no conteúdo Balanceamento de Reações Químicas. A proposta consistiu na elaboração de um jogo sobre o conteúdo e que pudesse ser aplicado nas aulas de química, facilitando a aprendizagem dos alunos neste conteúdo.

A proposta foi dividida em 2 etapas. A $1^{\text {a }}$ etapa consistiu na confecção do jogo. Os pibidianos ficaram responsáveis por esta etapa, no qual foi necessário realizar uma pesquisa para a seleção das reações químicas a serem balanceadas. A $2^{\mathrm{a}}$ etapa foi realizada a aplicação do jogo, que teve como objetivo que os alunos revisassem o conteúdo de Balanceamento de Reações Químicas, uma vez que já havia sido trabalhado pela professora em sala de aula.

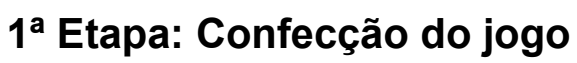

Inicialmente, realizou-se uma pesquisa e selecionou-se 13 reações químicas. $O$ jogo foi constituído por 13 fichas contendo as substâncias reagentes e 13 fichas contendo os produtos. As reações foram impressas em papel branco, tamanho A4 e cortadas, separando-se os reagentes dos produtos. As fichas foram coladas em cartolina colorida. A cor do verso das fichas dos reagentes era diferente da cor do verso das fichas dos produtos, para que durante o jogo os alunos pudessem identificar as fichas reagentes $e$ as fichas produtos e montar mais facilmente as reações. Além disso, foi confeccionado as setas e os números (coeficientes estequiométricos), necessários para montar a equação química e realizar o seu balanceamento (Figura 2). No total foram confeccionados 4 kits do jogo, para ser utilizado em sala de aula. 
Figura 2 - Peças do jogo Balanceamento Químico.

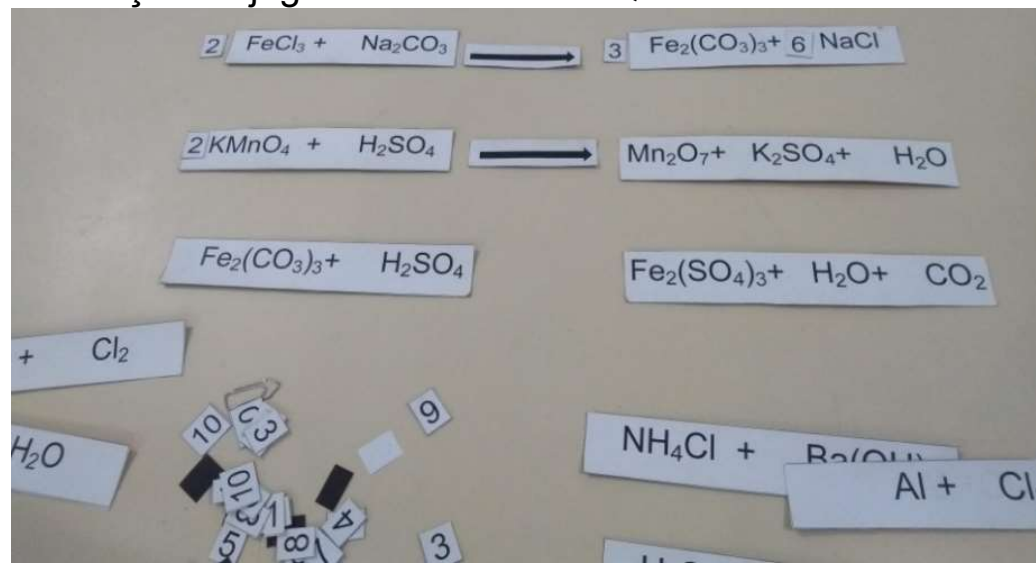

Fonte: Elaborado pelo autor.

\section{$2^{a}$ Etapa: Aplicação do jogo}

A aplicação do jogo ficou sob responsabilidade dos bolsistas juntamente com a professora supervisora. Uma bolsista do PIBID acompanhou as aulas teóricas para analisar o grau de dificuldade dos alunos no conteúdo Balanceamento de Reações Químicas e, assim, conseguir confeccionar o jogo de acordo com a realidade das turmas em que seria aplicado o material.

No dia da aplicação, cada turma foi dividida em 4 grupos, contendo no máximo 7 alunos cada. As regras do jogo foram explicadas aos alunos e, na sequência, cada grupo recebeu um envelope contendo as fichas de reagentes e produtos, as setas e os números (coeficientes estequiométricos) para realizarem o balanceamento. Os alunos deveriam montar a reação e, em seguida, balanceá-la corretamente. Foi distribuída uma folha A4 para cada grupo, no qual eles deveriam transcrever as reações montadas e balanceadas corretamente. O jogo terminava quando não existissem mais fichas sobre a mesa, ou seja, quando todas as reações fossem montadas e balanceadas.

\section{ANÁLISE DOS DADOS}

Para a análise da metodologia da construção de um videoclipe sobre a Tabela Periódica, utilizou-se as respostas fornecidas pelos estudantes ao questionário, a partir de uma abordagem qualitativa e adotando a técnica de Análise de Conteúdo (BARDIN, 1977). Nesse sentido, as respostas foram 
classificadas, agrupadas e categorizadas conforme semelhanças existentes no discurso. As categorias foram criadas após a leitura e análise de todos os textos.

Para a análise do jogo Balanceamento Químico utilizou-se a observação e o registro das impressões dos alunos, que foi realizada no diário de bordo dos bolsistas do PIBID.

\section{Resultados e discussão}

Neste capítulo serão apresentados e discutidos os resultados obtidos da aplicação das duas metodologias alternativas desenvolvidas neste trabalho, bem como os impactos na aprendizagem dos estudantes.

\section{RESULTADOS E DISCUSSÃO DA CONSTRUÇÃO DE UM VIDEOCLIPE SOBRE TABELA PERIÓDICA}

A proposta de criação do videoclipe sobre a Tabela Periódica foi bem aceita pelos alunos. Eles se mostraram motivados e dispostos a realizar um trabalho com qualidade. Acredita-se que essa aceitação foi devido ao fato de ser uma aula diferenciada.

Durante a criação da paródia observou-se a falta de conhecimento da maioria dos alunos com relação ao conteúdo Tabela Periódica. Em teoria, no $9^{\circ}$ ano do Ensino Fundamental, os alunos deveriam estudar sobre a Tabela Periódica e chegar no Ensino Médio possuindo algum conhecimento sobre o assunto. Porém, muitos alunos relataram, durante as aulas, que estudaram pouco sobre os conteúdos de química. Acredita-se que isso ocorre, devido ao fato de, no $9^{\circ}$ ano, a disciplina de ciências englobar conteúdos de química e física juntos. Segundo Diniz Júnior, Oliveira e Santana (2011), o ensino de ciências no $9^{\circ}$ ano tem que ser considerado como imprescindível aos conhecimentos dos estudantes, para que os mesmos tenham melhores desempenhos ao ingressar no Ensino Médio, levando noções amplas a respeito das matérias, não tendo tanta dificuldade em aprender Química e Física. Os alunos, durante o preparo do trabalho, mostravam a paródia feita à professora e aos pibidianos e quando havia algum erro, era solicitada a 
correção. Os trechos de algumas paródias criadas pelos alunos estão apresentados no Quadro 2.

Quadro 2 - Trechos de paródias criadas pelos alunos.

\begin{tabular}{|c|c|}
\hline Grupo & Trecho da paródia \\
\hline 1 & $\begin{array}{l}\text { "Vamos falar da Tabela Periódica, } \\
\text { Pra entender ela tem que ter uma lógica, } \\
\text { É dividida em período e família [...]" }\end{array}$ \\
\hline 2 & $\begin{array}{l}\text { "[...] Não sabia quem havia criado, } \\
\text { Hoje em dia já tá decorado, } \\
\text { Todos os elementos: metais e ametais, } \\
\text { Sintéticos e também naturais [...]" }\end{array}$ \\
\hline 3 & $\begin{array}{l}\text { "[...] Dimitri criou, mas não ficou, } \\
\text { Moseley chegou e atualizou [...]" } \\
\text { "[...] Tem gases nobres e os lantanídeos, } \\
\text { Halogênios e os actinídeos. } \\
\text { Quem disse que a matéria é complicada, } \\
\text { Tenho certeza que não estudou nada. } \\
\text { Essas lições deixadas por fazer, } \\
\text { Meu Deus! Como que tu quer aprender? [...]" }\end{array}$ \\
\hline
\end{tabular}

Fonte: Elaborado pelo autor.

No dia da apresentação para a turma, os alunos estavam animados e ansiosos para mostrar o seu videoclipe e assistir o dos colegas. De acordo com Barboza e colaboradores (entre 2016 e 2020), além da motivação, o uso dos recursos midiáticos, em especial o vídeo, desperta a criatividade do aluno estimulando-o à construção de conhecimentos, favorecendo ao professor conduzir o aluno a uma aprendizagem mais significativa e próxima do seu cotidiano. Além disso, o "fazer" os vídeos proporciona aos educandos uma reflexão para com as questões propostas, pois leva o aluno a refletir e sistematizar o conteúdo já aprendido em outros momentos.

Os alunos avaliaram a metodologia desenvolvida respondendo a um questionário. As respostas dos 132 alunos que participaram da atividade estão apresentadas e discutidas a seguir.

$\mathrm{Na}$ primeira questão do questionário perguntou-se se os alunos haviam gostado da maneira como a metodologia havia sido trabalhada e pediu-se que os mesmos justificassem sua resposta. Os resultados estão apresentados no gráfico da Figura 3. 
Figura 3 - Resultado da pergunta: "Você gostou da metodologia que foi trabalhada?"

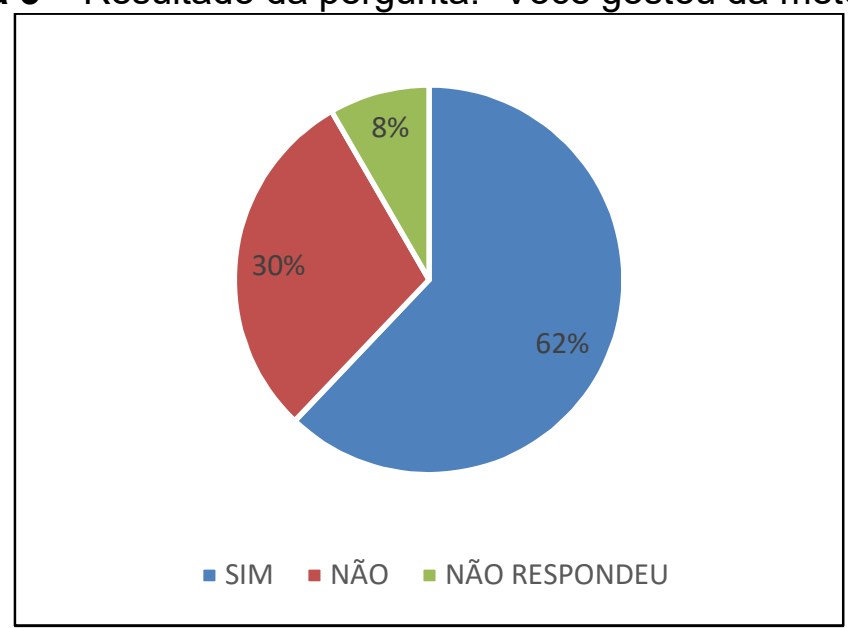

Fonte: Dados do autor.

Analisando-se o gráfico da Figura 3, observa-se que a maioria dos alunos gostou da metodologia desenvolvida. Segundo Moreira, Santos e Coelho (2014), a música como elemento lúdico pode ser utilizada para promover interação, motivação e criar uma atmosfera de aprendizagem mais prazerosa e descontraída. As justificativas apresentadas pelos alunos que disseram que gostaram da metodologia, foram divididas em categorias, de acordo com a metodologia proposta por Bardin (1977) e estas estão apresentadas no Quadro 3.

Quadro 3 - Categorização das respostas dos alunos que afirmaram gostar da metodologia de construção de um videoclipe sobre a Tabela Periódica.

\begin{tabular}{|l|l|l|}
\hline Categoria & $\begin{array}{l}\text { Quantidade } \\
\text { de alunos }\end{array}$ & $\begin{array}{l}\text { Algumas respostas que se enquadram na } \\
\text { categoria }\end{array}$ \\
\hline $\begin{array}{l}\text { Diversão } \\
\text { atração }\end{array}$ & 56 & $\begin{array}{l}\text { "Gostei muito, foi bem diferente bastante atrativo." } \\
\text { "Divertido." } \\
\text { "A aula foi divertida e diferente." }\end{array}$ \\
\hline $\begin{array}{l}\text { Promove } \\
\text { trabalho em } \\
\text { grupo }\end{array}$ & 7 & $\begin{array}{l}\text { "Amei, além de ser uma aula diferencial, } \\
\text { aprendemos muito e tivermos que trabalhar em } \\
\text { grupo." } \\
\text { "A aula foi boa, pois pudermos trabalhar em grupo } \\
\text { com os amigos." } \\
\text { "Gostei da aula, porque trabalhei em grupo." }\end{array}$ \\
\hline $\begin{array}{l}\text { Promove } \\
\text { Compreensão } \\
\text { do conteúdo }\end{array}$ & 19 & $\begin{array}{l}\text { "Ajudou na compreensão do conteúdo." } \\
\text { entendimento do conteúdo." proporcionou um bom } \\
\text { "Ajudou a tirar dúvidas do conteúdo." }\end{array}$ \\
\hline
\end{tabular}

Fonte: Dados do autor. 
Sobre a primeira categoria, diversão e atração, já se esperava que a maioria dos alunos gostassem da metodologia por ser algo diferente das aulas teóricas. Segundo Watanabe, Baldoria e Amaral (2018), o vídeo mescla diversas linguagens que podem se transformar em atividades desafiadoras e instigantes para os alunos. Saber selecionar informações, gravar e produzir vídeos são atividades que podem contribuir para tirar o aluno do seu papel passivo, motivando-o a aprender.

Alguns alunos destacaram o trabalhar em grupo, referente a segunda categoria, como um fator que tenha feito eles gostarem da metodologia. De acordo com Moran (2009), a produção de vídeo pelos alunos estimula a participação e as discussões, o desenvolvimento da criatividade, melhora a fixação do conteúdo e, principalmente, auxilia na comunicação e interação entre os componentes do grupo de trabalho. O trabalho em grupo ainda é desafiador para os alunos, pois no processo de construção de uma atividade em parceria é importante expor a opinião e escutar a do outro para se chegar num consenso. Muitos alunos ainda apresentam dificuldade em interagir uns com os outros para a realização de uma atividade. Durante todo período de elaboração do trabalho, sempre era discutido sobre a importância do trabalho em grupo. É através dele que o aluno se desenvolve como cidadão, aprende a ouvir e respeitar a opinião do outro.

Sobre a terceira categoria, "Promove a compreensão do conteúdo", Silva, Leite e Leite (2016) afirmam que o registro em vídeo permite ao aluno expressar suas percepções sobre o objeto pesquisado, contribuindo para o processo de ensino e aprendizagem dos conteúdos em sala de aula. Além disso, quando o aluno faz o que gosta, melhor é a construção do seu conhecimento.

As justificativas dos alunos que afirmaram não gostar da metodologia, também foram divididas em categorias e estão apresentadas no Quadro 4. 
Quadro 4 - Categorias das justificativas apresentadas pelos alunos que afirmaram não gostar da metodologia de construção de um videoclipe sobre a Tabela Periódica.

\begin{tabular}{|l|l|l|}
\hline Categoria & $\begin{array}{l}\text { Quantidade } \\
\text { de alunos }\end{array}$ & $\begin{array}{l}\text { Algumas respostas que se enquadram na } \\
\text { categoria }\end{array}$ \\
\hline Muito trabalhoso & 27 & $\begin{array}{l}\text { "Muito trabalhoso." } \\
\text { "Deu muito trabalho." } \\
\text { "Foi bem difícil." }\end{array}$ \\
\hline $\begin{array}{l}\text { Não saber trabalhar } \\
\text { em grupo }\end{array}$ & 7 & $\begin{array}{l}\text { "Muitos ainda não sabem trabalhar em grupo." } \\
\text { "Algumas pessoas do grupo não ajudaram } \\
\text { muito." } \\
\text { "Tivemos muitas discussões em relação a } \\
\text { música." }\end{array}$ \\
\hline $\begin{array}{l}\text { Dificuldade na } \\
\text { criação da paródia }\end{array}$ & 5 & $\begin{array}{l}\text { "Tivermos que pesquisar, estudar muito para } \\
\text { criar a paródia, não gostei." } \\
\text { "Algumas pessoas não ajudaram a criar a letra } \\
\text { da música." } \\
\text { "Não gostei, pois a professora poderia dar a } \\
\text { letra da música." }\end{array}$ \\
\hline
\end{tabular}

Fonte: Dados do autor.

Um número significativo de alunos afirmou ter achado a metodologia trabalhosa. Observou-se que os alunos ainda não apresentam autonomia na pesquisa. A todo momento pediam ajuda para a professora e aos pibidianos. Os alunos foram orientados a pesquisar para solucionar suas dúvidas, não foi fornecido respostas prontas. Segundo Rinaldi (2018), um aluno que possui autonomia torna-se um indivíduo proativo, capaz de resolver mais facilmente os problemas, dentro e fora do contexto educacional, e aprende a ser crítico quanto ao que pensa e produz.

Sobre a segunda categoria, "Não saber trabalhar em grupo", já era esperado que alguns alunos apresentariam esse fator como aspecto que dificultasse a realização do trabalho. Isso porque, durante o preparo, muitos grupos procuraram a professora para reclamar que alguns alunos não estavam contribuindo para a realização do trabalho ou que o trabalho em grupo não estava funcionando bem. De acordo com Abrahão (2010), a comunicação se torna fundamental para resolver dificuldades que estejam implícitas ou não na construção conjunta de uma atividade grupal. Quando o grupo encara as dificuldades que surgem e passam a enfrentá-las buscando soluções, os dilemas são criados e um espaço para uma construção cooperativa passa a ser estabelecido. 
Sobre a dificuldade na construção da paródia, foi destacado anteriormente que os alunos deveriam pesquisar sobre o assunto do trabalho para criar a paródia, pois muitos estavam com dificuldades no conteúdo de Tabela Periódica, provavelmente por falta de conhecimentos prévios. Acreditase que, por isso, acharam complicada essa etapa do trabalho.

$\mathrm{Na}$ segunda questão, apresentou-se alguns itens e pediu-se que os alunos marcassem aqueles que tiveram maior dificuldade durante a realização do trabalho. Os resultados estão apresentados no gráfico da Figura 4.

Figura 4 - Resultados da pergunta: "Quais dos seguintes itens você teve dificuldades ao realizar a paródia?"

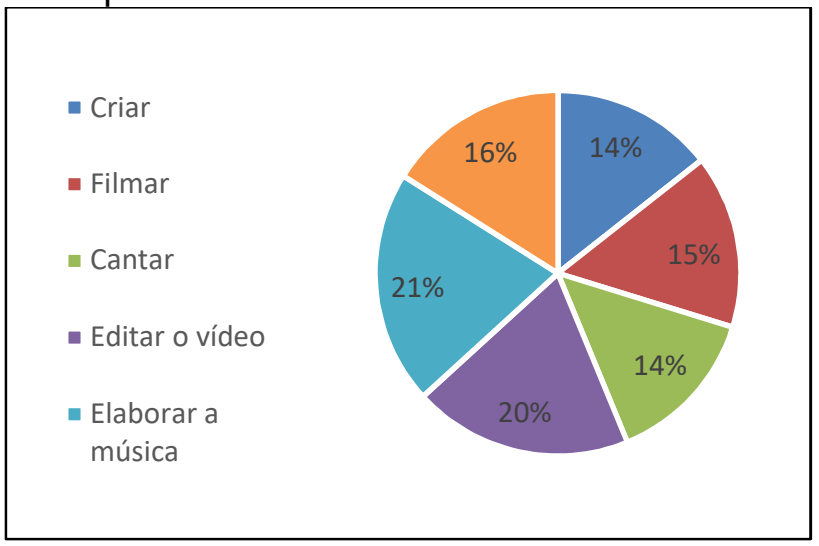

Fonte: Dados do autor.

É importante salientar que um único aluno marcou mais de uma resposta, os demais assinalaram somente um item. Observa-se que as maiores dificuldades apontadas pelos alunos foram elaborar a música (paródia) e editar o vídeo. Para elaborar a paródia, os alunos deveriam compreender o conteúdo sobre Tabela Periódica, e, mesmo após a explicação teórica, muitos estavam com dificuldade no assunto. A principal dúvida observada foi a respeito dos períodos e famílias. Muitos estavam fazendo confusão: não sabiam se as linhas horizontais eram os períodos ou as famílias, e o mesmo acontecia com as colunas da Tabela Periódica. Além disso, não compreenderam muito bem o que os períodos e as famílias indicam sobre a estrutura dos átomos, que são, respectivamente, o número de camadas e o número de elétrons na última camada. Acredita-se que, por isso, um grande número de alunos marcou o item elaboração da música (paródia) como a maior dificuldade apresentada. Além 
disso, tiveram que pesquisar sobre o assunto e ainda se nota a dificuldade que os alunos apresentam em ter autonomia durante a pesquisa.

A edição do vídeo se tornou um problema para os alunos, pois muitos não possuem recursos tecnológicos, como celular ou computador, e/ou internet disponível. De acordo com a pesquisa TIC Educação, realizada em 2019, 39\% dos estudantes de escolas públicas urbanas não têm computador ou tablet em casa (OLIVEIRA, 2020). Para contornar este problema durante a execução da metodologia, um dos pibidianos ajudou os alunos na edição dos vídeos, utilizando seu computador pessoal e a internet disponível na escola.

$\mathrm{Na}$ terceira questão perguntou-se o que poderia ser melhorado na metodologia proposta. As respostas dos alunos foram divididas em categorias, e estão apresentadas no Quadro 5. Do total de alunos que responderam o questionário (132), 50 não responderam esta questão.

Quadro 5 - Categorias das respostas apresentadas pelos alunos sobre o que poderia ser melhorado na metodologia proposta.

\begin{tabular}{|c|c|c|}
\hline Categoria & $\begin{array}{l}\text { Quantidade } \\
\text { de alunos }\end{array}$ & $\begin{array}{l}\text { Algumas respostas que se enquadram na } \\
\text { categoria }\end{array}$ \\
\hline $\begin{array}{l}\text { Nada precisa ser } \\
\text { melhorado }\end{array}$ & 44 & $\begin{array}{l}\text { "Foi legal." } \\
\text { "Não precisa ser melhorado". } \\
\text { "Nada"" }\end{array}$ \\
\hline $\begin{array}{l}\text { Tempo para a } \\
\text { execução } \\
\text { atividade }\end{array}$ & 17 & $\begin{array}{l}\text { "Mais tempo para o trabalho." } \\
\text { "O tempo foi muito curto." } \\
\text { "Mais tempo para a elaboração do trabalho, } \\
\text { ficamos muito sem tempo, pois muitos dos } \\
\text { colegas trabalha no turno da tarde." }\end{array}$ \\
\hline Comodismo & 9 & $\begin{array}{l}\text { "Receber as paródias prontas." } \\
\text { "O vídeo poderia ser editado pelo estagiário." } \\
\text { "O estagiário ajudar na paródia." }\end{array}$ \\
\hline $\begin{array}{l}\text { Dificuldades com } \\
\text { edição/filmagem }\end{array}$ & 12 & $\begin{array}{l}\text { "Só eu que editei o vídeo." } \\
\text { "Foi difícil editar no programa." } \\
\text { "Tudo foi muito bom, porém só tivemos } \\
\text { dificuldades para filmar, pois o grupo todo tinha } \\
\text { que aparecer no vídeo." }\end{array}$ \\
\hline
\end{tabular}

Fonte: Dados do autor.

Nota-se que um número significativo de alunos afirmou que nada precisava ser melhorado, pois gostaram da proposta de trabalho. Isso foi observado durante a construção do videoclipe. Muitos alunos estavam motivados e se mostraram interessados em realizar um trabalho com qualidade. 
A segunda categoria, "Tempo para execução da atividade", é um empecilho citado por eles na maioria dos trabalhos. Procuramos sempre apresentar a proposta de um trabalho com antecedência, para que os alunos tenham no mínimo 1 mês para realizá-lo. Porém, os mesmos costumam se preocupar com a tarefa quando a data de apresentação já está próxima. Não procrastinar é algo que deve ser trabalhado nos alunos. De acordo com Terada (2020), é mais provável que os alunos adiem um projeto se não entenderam como começar. É importante que o professor verifique se todos os alunos conhecem suas expectativas e os requisitos da tarefa e, muitas vezes, é melhor colocar instruções por escrito para que eles possam consultá-las conforme necessário.

A terceira categoria mostra o comodismo apresentado durante a realização de um trabalho. Muitos alunos destacaram a dificuldade na construção da paródia, porque deveriam pesquisar sobre o assunto Tabela Periódica. A pesquisa não deveria ser um problema, pois os alunos estão em processo de construção do conhecimento e a mesma é um fator essencial para que se atinja os objetivos de aprendizagem. No processo escolar, deveria ser algo com que os alunos estivessem acostumados. Entretanto, ainda se observa a resistência dos estudantes quando é necessário realizar uma pesquisa para a confecção de um trabalho. De acordo com Portilho e Almeida (2008), a pesquisa escolar é um importante instrumento metodológico de ensino e aprendizagem, sendo que, através dela é possível desenvolver ações que levem a interdisciplinaridade, palavra de ordem no atual contexto educacional. Sua utilização induz ao desenvolvimento de competências e habilidades indispensáveis à formação do educando. Sua prática permite que o aluno aprenda ao transformar informação em conhecimento.

Sobre a quarta categoria, "Dificuldades com edição/filmagem", foi solicitado, durante a explicação da proposta, que todos os alunos deveriam aparecer no videoclipe. Mas, para isso, o vídeo deveria ser editado, pois em um momento um determinado aluno estaria filmando e em outro estaria aparecendo na filmagem. Como já foi destacado anteriormente, a edição do 
vídeo foi um problema para os alunos. Acredita-se que por isso, tenham destacado essa dificuldade como sugestão de melhoria do trabalho.

$\mathrm{Na}$ quarta questão perguntou-se qual foi o maior incentivo para a realização do trabalho de produção do videoclipe sobre a Tabela Periódica. As respostas dos alunos foram divididas em categorias e estão apresentadas no Quadro 6. Do total de alunos que respondeu o questionário (132), 50 não responderam esta questão.

Quadro 6 - Categorias das respostas apresentadas pelos alunos sobre o maior incentivo para a realização do trabalho de produção do videoclipe sobre a Tabela Periódica.

\begin{tabular}{|l|l|l|}
\hline Categoria & $\begin{array}{l}\text { Quantidade } \\
\text { de alunos }\end{array}$ & Algumas respostas que se enquadram na categoria \\
\hline $\begin{array}{l}\text { Motivação } \\
\text { pela Nota }\end{array}$ & 44 & $\begin{array}{l}\text { "O maior incentivo foi a nota por valer 12 pontos." } \\
\text { "Nota." }\end{array}$ \\
\hline $\begin{array}{l}\text { Motivação } \\
\text { pelo } \\
\text { aprendizado }\end{array}$ & 33 & $\begin{array}{l}\text { "Aprender muito." } \\
\text { "Aprender mais sobre o conteúdo." } \\
\text { "Aprender sobre a tabela periódica." }\end{array}$ \\
\hline $\begin{array}{l}\text { Motivação } \\
\text { pelo trabalho } \\
\text { em grupo }\end{array}$ & 5 & $\begin{array}{l}\text { "Por que pudemos trabalhar em grupo." } \\
\text { "Trabalhar em grupo." } \\
\text { "O trabalho em grupo." }\end{array}$ \\
\hline
\end{tabular}

Fonte: Dados do autor.

Dentre todas as respostas apresentadas, a que apareceu com mais frequência, como incentivo, foi a nota atribuída para a atividade. A maior motivação dos alunos para a realização do trabalho ainda é a nota, algo que deveria ser modificado, pois o mais importante na realização de um trabalho é a aquisição de conhecimento, ou deveria ser. Uma pesquisa realizada por Ulhôa e colaboradores (2008) mostrou que a maior motivação, dos alunos, para a realização de um trabalho é a pontuação que o mesmo vale. Destaca-se a fala de um aluno: "Eu acho que todo mundo aqui faz por causa dos pontos de exercício. Se não tivesse ponto o povo ia fazer 'pros coco', meio largado, e por valer ponto, o povo faz com mais interesse". A fala do aluno evidencia que na realização de um trabalho de pesquisa a pontuação que o professor atribuí é o que vai determinar o esforço do estudante na execução da atividade, pouco importando nesta situação se houve ou não o aprendizado, mas sim se o educando obteve ou não a nota máxima. 
A segunda categoria, "Motivação pelo aprendizado", é um dos objetivos da proposta apresentada. Desde o início, o intuito era que os alunos desenvolvessem o trabalho e, com isso, aprendessem mais sobre o conteúdo da Tabela Periódica. De acordo com Fabri e Giacomini (2017), não é fácil motivar os alunos, por isso, cada vez mais, professores e pesquisadores propõem estratégias de ensino que têm o propósito de despertar em seus alunos a intenção para aprender e, além disso, podem promover o aprendizado mais significativo.

A terceira categoria, "Motivação pelo trabalho em grupo", foi um aspecto que chamou atenção nas respostas do questionário. Alguns alunos afirmaram terem gostado da metodologia devido ao trabalho em grupo com os colegas. As atividades grupais são importantes para o desenvolvimento de um cidadão crítico, que sabe ouvir e respeitar a opinião do outro, além de expressar as suas ideias.

$\mathrm{Na}$ quinta questão do questionário, solicitou-se que os alunos atribuíssem uma nota de 1 (péssimo) a 5 (excelente) se a construção da paródia sobre a Tabela Periódica de alguma forma contribuiu para o seu conhecimento. Os resultados para esta questão estão apresentados no gráfico da Figura 5.

Figura 5 - Resultados da questão: "Atribuir uma nota de 1 a 5 se a construção da paródia da Tabela Periódica de alguma forma contribuiu para o seu conhecimento".

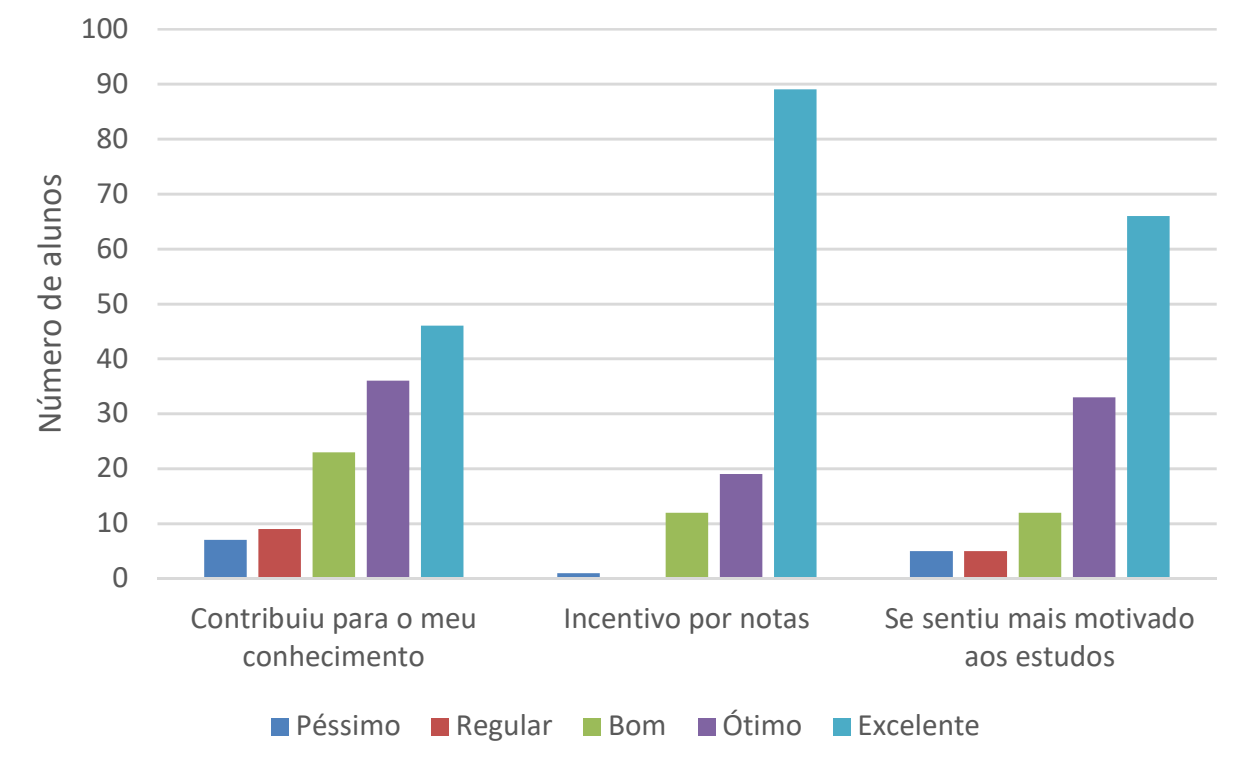

Fonte: Dados do autor. 
Nota-se que um grande número de alunos destacou que a maior contribuição para a realização do trabalho foi o incentivo por notas, como já observado anteriormente. Segundo Erig e Junges (2020), os alunos estudam porque ainda possuem a ideia de que necessitam passar de ano, ter um conhecimento básico e notas mesmo que não haja pressão da família para isso. De acordo com Biadola (2002), é importante que se estimule o aluno, elogiando-o e atribuindo notas em avaliações e em outras atividades para que os alunos tenham interesse pela aprendizagem. Gradativamente, o professor deverá ir retirando estes estímulos fazendo com que as notas deixem de ser tão importantes para o aluno.

Um número significativo de alunos afirmou que, com a realização do trabalho, se sentiu mais motivado aos estudos e contribuiu para o conhecimento do conteúdo Tabela Periódica. Esse resultado mostra que a proposta conseguiu atingir seu objetivo, pois contribuiu para que os alunos se sentissem mais motivados e fazendo com que compreendessem melhor o conteúdo em estudo.

\section{RESULTADOS E DISCUSSÃO DA APLICAÇÃO DO JOGO BALANCEAMENTO QUÍMICO}

Durante as aulas, observou-se que os alunos apresentavam dificuldade ao balancear as reações químicas. Segundo Costa e Souza (2013), os alunos apresentam dificuldades em escrever ou balancear as reações, devido a forma como o tema é abordado em sala de aula, o que leva o estudante a imaginar a Química como uma ciência abstrata, dificultando consideravelmente 0 aprendizado, além de transmitir o conceito errôneo de que o estudo da Química é meramente decorativo. Pensando em tornar o ensino do conteúdo Balanceamento de Reações Químicas mais atrativo e fácil de ser compreendido, foi solicitado, pela professora supervisora, que os bolsistas do PIBID criassem um jogo sobre o assunto, para que os alunos compreendessem melhor o conteúdo. Em geral, a linguagem científica do professor não é facilmente compreendida pelos alunos durante as aulas expositivas e os jogos podem promover discussões em que ocorrem interações entre as linguagens 
do professor e as dos estudantes, facilitando o estabelecimento de significados comuns a ambos e consequentemente a aprendizagem dos conceitos científicos trabalhados nos jogos (FOCETOLA et al., 2012, p. 249).

Durante a aplicação do jogo, os alunos se mostraram interessados e participaram ativamente da metodologia proposta. De acordo com Santos e Michel (2009), a principal vantagem do uso de jogos didáticos envolve a motivação gerada pelo desafio do jogo, acarretando o desenvolvimento de estratégias de resolução de problemas, a avaliação das decisões tomadas e a familiarização com termos e conceitos apresentados no material.

No início, alguns apresentaram dificuldade em montar e balancear as reações químicas. Com o auxílio dos bolsistas do PIBID, os alunos foram entendendo a proposta e conseguiram realizar o balanceamento das reações do jogo. A metodologia mostrou-se efetiva, pois além de atrair e motivar os alunos, contribuiu para que eles entendessem melhor o conteúdo.

Ao final do jogo, perguntou-se aos alunos quais foram as impressões que eles tiveram da proposta desenvolvida. As respostas foram registradas e algumas estão apresentadas a seguir.

Aluno 1: "Foi bom o trabalho em equipe aprimoramento do
conhecimento"
Aluno 2: "Legal e interessante pois é uma forma de estimular o aluno."
Aluno 3: "Me ajudou a tirar algumas dúvidas sobre o assunto."
Aluno 4: "Está me ajudando a entender mais sobre o assunto."
Aluno 5: "O jogo nos fez trabalhar em equipe e revisar o conteúdo do
trimestre anterior."
Aluno 6: "Foi mais um aprendizado."
Aluno 7: "Está me ajudando a entender um pouco mais sobre
balanceamento".

Foi notável a grande aceitação do jogo Balanceamento Químico. Alguns alunos destacaram o trabalho em equipe. Durante o desenvolvimento da metodologia observou-se que os alunos trabalharam bem em grupo. Um aluno ajudava o outro e, com isso, conseguiram atingir o objetivo do jogo, que foi montar e balancear todas as reações propostas no kit. Segundo Cunha (2012), os jogos melhoram a socialização em grupo, pois, em geral, são realizados em conjunto com seus colegas. 


\section{Considerações finais}

Os resultados obtidos sugerem que as metodologias alternativas de ensino atuam como ferramentas eficientes nos processos de ensino e aprendizagem da disciplina de Química.

A produção da paródia e do videoclipe mostrou-se satisfatória e ocorreu de forma agradável e proveitosa. Durante as aulas, observou-se que alguns alunos passaram a desenvolver uma melhor relação com a Tabela Periódica e os elementos químicos, pois os mesmos se lembravam das paródias. Em alguns momentos, para lembrar o que os períodos e famílias indicavam sobre a estrutura dos átomos, os alunos cantavam trechos da música criada por eles próprios.

Os jogos, no cotidiano escolar, contribuem de forma significativa, uma vez que os alunos se envolvem e interagem com a disciplina, tornando o ensino mais fácil e dinâmico. Os mesmos foram motivados pela professora supervisora e pelos bolsistas do PIBID, para que os objetivos da metodologia fossem atingidos. O uso de jogos pode contribuir de forma positiva na apropriação dos conteúdos, gerando uma aprendizagem significativa. Durante o jogo Balanceamento Químico os alunos puderam sanar suas dúvidas e a transmissão do conhecimento deixou de ser objetiva e passou a ser ativa e significativa.

A participação dos bolsistas do PIBID, no auxílio das aulas, facilitou o desenvolvimento de metodologias alternativas de ensino, uma vez que o professor encontra certas dificuldades no seu dia a dia para o preparo de atividades deste tipo, como falta de tempo devido à parte burocrática do ensino, que deve ser cumprida. Além disso, os bolsistas puderam participar de todo o processo de ensino e aprendizagem, o que contribuiu para a sua formação inicial como aluno do curso de Licenciatura em Química. Em todo momento, buscavam ajudar os alunos a solucionarem suas dúvidas e participaram ativamente das aulas, ou seja, vivenciaram a realidade da futura profissão, que é o objetivo do PIBID.

As metodologias propostas tiveram seus objetivos concretizados, visto que a função educativa, agregada ao aspecto lúdico, foi observada durante a 
aplicação. De certo modo, houve o entendimento e a compreensão de conceitos complexos e abstratos a partir do estímulo ao raciocínio, da motivação e da interação entre alunos, professora e bolsistas do PIBID.

\section{Agradecimentos}

Agradecemos a Capes pelas bolsas e financiamento do projeto.

\section{Referências bibliográficas}

ABRAHÃO, E. F. Reflexões sobre o trabalho em grupo com licenciandos de uma universidade particular de São Paulo. 2010. 56 f. Trabalho de graduação interdisciplinar - Universidade Presbiteriana Mackenzie, São Paulo, 2010.

BARBOSA, K. D. L. et al. Produção de vídeos e seu uso para o ensino de matemática: uma experiência vivenciada pelo PIBID. [entre 2016 e 2020]. Disponível em: http://www.fef.br/upload_arquivos/geral/arq_58822b158d755.pdf. Acesso em: 07 set. 2020.

BARDIN, L. Análise de conteúdo. Lisboa: Edições 70, 1977.

BIADOLA, $V$. Motivação para aprendizagem dos alunos do ensino médio de uma escola: estudo de caso. 2002. 80 f. Dissertação (Mestrado em Engenharia de Produção) - Universidade Federal de Santa Catarina, Florianópolis, 2002.

BRASIL. Ministério da Educação. Secretaria de Educação Média e Tecnológica. Parâmetros Curriculares Nacionais. Brasília: MEC, 1997.

CAPES. Pibid - Programa Institucional de Bolsa de Iniciação à Docência. Disponível em: https://capes.gov.br/educacao-basica/capespibid/pibid. Acesso em: 10 ago. 2020.

COSTA, A. A. F.; SOUZA, J. R. T. Obstáculos no processo de ensino e de aprendizagem de cálculo estequiométrico. Amazônia/Revista de Educação em Ciências e Matemática, v.10, n. 19, p.106-116, 2013.

CUNHA, M. B. Jogos no Ensino de Química: Considerações Teóricas para sua Utilização em Sala de Aula. Química Nova na Escola, v. 34, n. 2, p. 92-98, 2012.

DINIZ JÚNIOR, A. I.; OLIVEIRA, C. B.; SANTANA, A. L. B. D. A importância da Química em Ciências do $9^{\circ}$ ano do Ensino Fundamental. In: CONGRESSO BRASILEIRO DE QUÍMICA, 51., 2011, São Luiz. Anais [...] Rio de Janeiro: Associação Brasileira de Química, 2011. Disponível em: 
http://www.abq.org.br/cbq/2011/trabalhos/6/6-230-

10222.htm\#: :text=Por\%20isso\%2C\%20acreditamos\%20que\%20o,em\%20apr ender\%20Qu\%C3\%ADmica\%20e\%20F\%C3\%ADsica. Acesso em: 02 ago. 2020.

ERIG, R.; JUNGES, F. Estudo da motivação dos alunos do $1^{\circ}$ ano do ensino médio para aprendizagem. In: SALÃO INTERNACIONAL DE ENSINO, PESQUISA E EXTENSÃO ANAIS, 11., 2019, Santana do Livramento. Anais [...] Rio Grande do Sul: Universidade Federal do Pampa, v. 11, n. 1, 2020.

FABRI, P. H.; GIACOMINI, R. A. Estudo da motivação do aluno no processo de ensino e aprendizagem promovida pelo uso de modelos moleculares, validado por meio de áudio e vídeo. Química Nova na Escola, v. 40, n. 3, p. 196-208, 2018.

FOCETOLA, P. B. M. et al. Os Jogos Educacionais de Cartas como Estratégia de Ensino em Química. Química Nova na Escola, v. 34, n. 4, p. 248-255, 2012.

GIL, A. C. Métodos e Técnicas de Pesquisa Social 5. ed. São Paulo: Atlas, 2006.

MALHEIROS, B. T. Metodologia da Pesquisa em Educação. Rio de Janeiro: LTC, 2011. p. 31, 32, 108.

MORAN, J. M. Vídeos são instrumentos de comunicação e de produção. Entrevista ao Jornal do Professor. 2009. Disponível em: http://www.eca.usp.br/prof/moran/site/textos/tecnologias eduacacao/videos.pdf. Acesso em: 07 set. 2020 .

MOREIRA, A. C.; SANTOS, H.; COELHO, I. S. A música na sala de aula: A música como recurso didático. Unisanta Humanitas, v. 3, n. 1, p.41-61, 2014.

OLIVEIRA, E. Quase $40 \%$ dos alunos de escolas públicas não têm computador ou tablet em casa, aponta estudo. Disponível em: https://g1.globo.com/educacao/noticia/2020/06/09/quase-40percent-dos-alunosde-escolas-publicas-nao-tem-computador-ou-tablet-em-casa-apontaestudo.ghtml. Acesso em: 10 ago. 2020.

PIEDADE, C. et al. Abordagem de reações químicas: uso do simulador PhET. Scientia Amazonia, v. 5, n. 2, p. 72-76, 2016.

PORTILHO, E.; ALMEIDA, S. Avaliando a aprendizagem e o ensino com pesquisa no Ensino Médio. Scielo, v.16, n. 60, p. 469-488, 2008.

RINALDI, R. A importância de desenvolver a autonomia dos alunos e 5 formas de fazer isso. 2018. Disponível em: https://gutennews.com.br/blog/2018/07/10/importancia-de-desenvolverautonomia-dos-alunos-e-5-formas-de-fazerisso/\#: :text=Um\%20aluno\%20que\%20possui\%20autonomia, ao\%20que\%20pe pen $\% 20$ e $\% 20$ produz.\&text=Al\%C3\%A9m\%20do\%20mais\%2C\%20j\%C3\%A1\% 
20passou,a\%20ler\%20apenas $\% 20$ os\%20cl\%C3\%A1ssicos. Acesso em: 07 set. 2020.

SANTOS, A. P. B.; MICHEL, R. C. Vamos Jogar uma SueQuímica? Química Nova na Escola, v. 31, n. 3, p. 179-183, 2009.

SILVA, J. L. et al. A Utilização de Vídeos Didáticos nas Aulas de Química do Ensino Médio para Abordagem Histórica e Contextualizada do Tema Vidros. Química Nova na Escola, v. 34, n. 4, p. 189-200, 2012.

SILVA, M. S. C. D.; LEITE, Q. S. S.; LEITE, B. S. O vídeo como ferramenta para o aprendizado de química: um estudo de caso no sertão pernambucano. Revista Tecnologias na Educação, ano 8, v.17, 2016.

SOARES, L. T. Uma abordagem interativa para o ensino da Tabela Periódica. 2019. 57 f. Monografia (Licenciatura em Química) - Universidade Federal Fluminense, Niterói.

TERADA, Y. Os psicólogos descobriram razões pelas quais os estudantes adiam um trabalho importante. Disponível em: https://porvir.org/como-ajudaros-alunos-a-deixar-a-procrastinacao-de-ladol. Acesso em: 11 ago. 2020.

VIGOTSKY, L. S. A formação social da mente: o papel do brinquedo no desenvolvimento. 7 ed. São Paulo: Martins Fontes Editores, 2007.

WATANABE, A.; BALDORIA, T.; AMARAL, C. L. C. O vídeo como recurso didático no ensino de química. Novas Tecnologias na Educação, v. 16, n. 1, p. 1-9, 2018.

\section{Sobre os autores}

\section{Ana Nery Furlan Mendes}

ana.n.mendes@ufes.br

Graduada em Química Industrial e Bacharel em Química pela UFRGS. Doutora em Química pela UFRGS, com período sanduíche na Universidad Autónoma de Barcelona. Atua como professora de Química no Departamento de Ciências Naturais da UFES. Membro do corpo docente permanente do Programa de Pós-Graduação em Ensino na Educação Básica da UFES. Desenvolve trabalhos de pesquisa na área de ensino de química, principalmente no desenvolvimento de materiais didáticos e paradidáticos, metodologias ativas e formação de professores.

\section{Carlos Duarte Silva}

carlosduartes.cat@gmail.com

Graduando em Licenciatura em Química pela Universidade Federal do Espírito Santo (UFES), campus São Mateus. Graduando em Administração pela Universidade Paulista. 


\section{Luciara Costa de Souza}

luciara.costadesouza@gmail.com

Graduanda em Licenciatura em Química pela Universidade Federal do Espírito Santo (UFES).

\section{Tamires Cesquine Alves}

tamirescesquine@gmail.com

Graduada em Licenciatura em Química pela Universidade Federal do Espírito Santo (UFES). Mestra em Ensino na Educação Básica pela Universidade Federal do Espírito Santo (UFES). Atua como professora de Química na Secretaria de Estado da Educação do Espírito Santo, no município de São Mateus-ES. 